\title{
Effect of Laser Cladding Processing Parameters on Nitinol's Clad Dimensions, Microstructure, and Hardness
}

\author{
Engy M. Zain ${ }^{1}{ }^{*}$, Ahmed Farid Youssef ${ }^{1}$, Ahmad El Sabbagh ${ }^{1}$, Sisa Pityana ${ }^{2}$, Mohamed A. Taha ${ }^{1}$ \\ ${ }^{1}$ Design and Production Engineering Department, Faculty of Engineering, Ain Shams University, Cairo, Egypt \\ ${ }^{2}$ National Laser Centre, The Council for Scientific and Industrial Research, Pretoria, South Africa \\ Email: *engy.zain@eng.asu.edu.eg
}

How to cite this paper: Zain, E.M., Youssef, A.F., El Sabbagh, A., Pityana, S., Taha, M.A. (2021) Effect of Laser Cladding Processing Parameters on Nitinol's Clad Dimensions, Microstructure, and Hardness. Materials Sciences and Applications, 12, 603-613. https://doi.org/10.4236/msa.2021.1212040

Received: November 21, 2021

Accepted: December 21, 2021

Published: December 24, 2021

Copyright (C) 2021 by author(s) and Scientific Research Publishing Inc. This work is licensed under the Creative Commons Attribution International License (CC BY 4.0)

http://creativecommons.org/licenses/by/4.0/

\begin{abstract}
Nickel Titanium alloy (Nitinol) is characterized by its good mechanical properties, good damping properties in addition to its distinctive shape-memory effect and superelasticity effect besides its great bio-mechanical compatibility and corrosion resistance. These properties have empowered its applications, particularly within the bio-medical and aerospace industry. Despite these exceptional properties, the manufacturing of Nitinol by conventional methods is exceptionally troublesome and costly and consequently must be inspected. Therefore, additive manufacturing specifically laser-based ones were used recently. In this research, the effect of processing parameters of laser cladding/ laser direct deposition on Nitinol's Microstructure, Hardness and Clad Dimensions was evaluated. Systematic characterization of Nitinol samples was done utilizing Optical Microscopy and Vickers hardness tester. Samples of Nitinol were synthesized with different processing parameters using laser cladding and its properties were investigated and compared to one another to get the optimum processing parameters to synthesize a near net shape, fully dense Nitinol component with reliable properties. The results showed that there's a processing parameter window at which the alloy possesses its best mechanical and functional properties which were of Laser power of value $1.25 \mathrm{Kw}$, Scan speed of $1.5 \mathrm{~m} / \mathrm{min}$ and powder deposition rate of 1.5/1.5 RPM, these conditions resulted in the formation of martensite phase which is responsible for its functional properties with $40 \%$ volume fraction and a hardness value of $598 \mathrm{HV}$.
\end{abstract}

\section{Keywords}

Nitinol, Shape Memory Alloy, Additive Manufacturing, Hardness, Microstructure 


\section{Introduction}

Nickel titanium is one of the most used shape memory alloys because of its outstanding functional properties which include shape memory and superelasticity effect. These two properties enable restoring strains up to $8 \%$ by loading and applying heat, respectively.

These two properties depend on a solid-solid phase transformation between martensite and austenite phases. In addition to these two features, biocompatibility, low stiffness and corrosion resistance of this alloy make it one of the best candidates for biomedical applications such as stents, bone implants and dental brackets [1] [2] [3] [4]. Although there is numerous alloy that is able to show the shape memory effect or the superelasticity, Nitinol and its alloys which contains additional alloying elements like $\mathrm{Cu}, \mathrm{Fe}$, etc. play an important role in the practical applications because of their high ductility and tensile strength when compared to other alloys [5] [6]. The development of science and technology led to the expansion of Nitinol usage in different fields, Nitinol is used in different kinds of elements used in automobile industry, household appliances, aircraft industry, and in many other fields of industry such as actuators, thermomechanical connectors, and temperature sensors [7].

Nitinol alloy has good damping properties, in addition to the good mechanical properties, when put in comparison to other shape memory alloys. Also, its strength and toughness can be further improved to reach the application of high strength application areas which means the expansion of the application range of the alloy [8].

Nitinol microstructure includes three different functioning phases, one of which is the martensite phase which is a low symmetry and complex-twinned monoclinic B19' structure. The other phase is Austenite which is a highly symmetric and ordered body centered structure. Martensite has a needle-like crystal structure, and is more ductile and softer than the austenite phase. The third phase is an intermediate phase that some grades of Nitinol has, it has a rhombohedral structure that possesses low transformation strain, and low temperature hysteresis and its formation can be related to any former cold work or aging processes or due to the addition of alloying elements such as iron [9].

In contrast to other conventional materials, there's no single fabrication method for NiTi parts or devices, many processing methods have been developed over the years for the manufacture of the shape memory and superelastic NiTi parts including powder metallurgy process and casting [1] [10]. Casting is one of the conventional methods that is commonly used, however, this process is accompanied by the high temperature melting that leads to the increase in the level of impurity pick up such as carbon, oxygen and as a result, the superelasticity and shape memory effect of the alloy is affected. One of the additional challenges that face the fabrication of nitinol is its super ductility that leads to excessive tool wear during the use of machining to get the final shape of the NiTi part needed [1]. Powder metallurgy is a technique from the conventional ones, that is used to 
manufacture near net shape parts. However, these techniques are limited in producing a complex geometry of parts and don't have full control over the size and shape of porosity [10].

Additive manufacturing turned out to be a very promising technique in producing highly complex geometries of $\mathrm{Ni}-\mathrm{Ti}$ with the required properties and a homogenous composition when compared to the conventional methods. One of the many advantages of the process is that it can produce final parts with high density and near net shape with little or no need for post processing processes. Additive manufacturing techniques especially laser-based ones are being intensively used to produce Ni-Ti parts [9] and the ability to adjustment of processing parameters to create certain properties made it better [11]. Laser Engineered Net Shaping (LENS) or also known as laser cladding is one of the most commonly used techniques among the numerous additive manufacturing techniques [12].

In LENS (also known as Direct Energy Deposition or Laser cladding), a laser beam is focused on a building platform and a coaxially sprayed metal powder which melts because of this laser beam and then solidifies on the platform [13].

In addition to the great advantages of additive manufacturing of Nitinol, there are also some disadvantages one of them is that its processing parameters greatly affect the final product and its properties, so to get a final product with high quality optimization of these parameters is a must [10]. In Nitinol's additive manufacturing, the processing parameters such as laser power, scan speed and powder related factors play an important role in determining the properties of the final product therefore optimizing these parameters is an essential step [9].

\section{Materials and Methods}

\subsection{Methodology}

In this work seven samples were prepared from elementary $\mathrm{Ni}$ and $\mathrm{Ti}$ powder with particle size 90 micron by Direct Laser Cladding with different laser conditions listed in Table 1 (varying laser power, laser speed and feed rate but with constant spot size $(2 \mathrm{~mm})$. The main objective of preparing these samples is to study the microstructure of the samples and identify the martensite phase, which is the low temperature phase, in each sample using optical microscopy in addition to measuring the hardness of all of the samples. Since the final geometry of the clad layer in Laser metal deposition process is important as it determines the processing strategy in additive manufacturing, the height and width of the clad track were measured to determine the effect of laser processing parameters. Depending on the microstructure result, volume fraction of martensite and Hardness values, the optimum laser parameter can be determined, and the varying parameters can be narrowed down to a short range. The combined effect of laser power $P$ and scan speed $V$ can be expressed by laser energy density $E$. It represents the amount of thermal energy provided to the spot as the laser beam pass it, was calculated with the following equation [14]. 
Table 1. Processing conditions of the samples.

\begin{tabular}{ccccc}
\hline Sample No. Laser power $(\mathrm{Kw})$ & $\begin{array}{c}\text { Scan Speed } \\
(\mathrm{m} / \mathrm{min})\end{array}$ & Ni/Ti RPM & $\begin{array}{c}\text { Laser energy density } \\
\left(\mathrm{J} / \mathrm{mm}^{3}\right)\end{array}$ \\
\hline $\mathrm{A}$ & 1.5 & 1.5 & $2 / 1.4$ & 30 \\
$\mathrm{~B}$ & 1.25 & 1.5 & $2 / 1.4$ & 25 \\
$\mathrm{C}$ & 1 & 1.5 & $2 / 1.4$ & 20 \\
$\mathrm{D}$ & 1.25 & 1.2 & $2 / 1.4$ & 31.25 \\
$\mathrm{E}$ & 1.25 & 1.4 & $2 / 1.4$ & 26.82 \\
$\mathrm{~F}$ & 1.25 & 1.6 & $2 / 1.4$ & 23.49 \\
$\mathrm{G}$ & 1.25 & 1.5 & $1 / 1.7$ & 25 \\
$\mathrm{H}$ & 1.25 & 1.5 & $1.5 / 1.5$ & 25 \\
\hline & & $E=\frac{P}{V h D}$ & &
\end{tabular}

where $E$ is laser energy density, $P$ is laser power, $V$ is scan speed, $H$ is hatch spacing and $D$ is Laser spot diameter.

\subsection{Materials and Equipment}

As for the substrate on which the powder is deposited, it is Ti-6Al-4V which means it has 6\% Aluminium and 4\% Vanadium in weight percent. And for the powder used, both Nickel and Titanium elementary powder with particle size 90 microns. The substrate material and the Nickel and Titanium powders were provided National laser centre in the CSIR, Pretoria in South Africa where the processing experiments took place.

The laser cladding operation was done using a $5 \mathrm{~kW}$ IPG YLS 5000 Fibre Laser system and it operates at a wavelength of $1070 \mathrm{~nm}$. The laser was controlled using an 8-axis Kuka robot arm and the powder material was deposited into the melt pool from the feeders which are connected to a jet powder nozzle located at a distance of $12 \mathrm{~mm}$ from the substrate. In order to measure the followability, the multi hopper feeding system was adjusted at a specific RPM then operated for sixty seconds then the container was measured before and after. Such measurement was done for the two powder materials at various RPMs as a calibration procedure to optimize the needed weight percentage via the change in RPM. And the carrier gas used was Argon which acts as a shielding gas to form a local inert gas atmosphere.

The substrate on which the powder is deposited is pre-heated at $500^{\circ} \mathrm{C}$ using a ceramic plate with coil heater and thermo couple connected to a simple circuit to control the temperature.

Cross-sections of the laser metal deposited samples were prepared for the microstructural investigation and Vickers hardness test. Therefore, the samples were mounted, finely polished, and treated with etching agent of composition 3.2 $\mathrm{mL} \mathrm{HF}, 12.2 \mathrm{~mL} \mathrm{HNO}_{3}$ and $84.6 \mathrm{~mL} \mathrm{H}_{2} \mathrm{O}$. The samples were tested on Ferox 
PL trinocular optical microscope and TE digital metallic Vickers hardness tester.

\section{Results and Discussion}

\subsection{Clad Track Geometry}

Clad height and width of single track were measured as shown in and results obtained in Table 2, height of the clad was measured from the substrate surface to the end of track height, while the width of the track was measured from the extreme points of the track perpendicular to the height measurement as shown in Figure 1.

In Figure 2, it's clearly observed that as the energy density increases, the height decreases while keeping the rate of deposited powder constant this trend is the same as the one reached by previous studies [15] [16] [17]. It was explained that this happens due to the rise in melt pool temperature which results in a better diffusion and hence the decrease in height of the clad. And for the width of the clad, tends to increase with the increase of the laser energy density at a constant powder deposition rate.

\subsection{Metallography Investigation}

Figure 3 shows optical micrographs of the samples, (A) shows the microstructure of sample A, the dendrite arms are clearly observed in this sample it's concentrated at the diffusion zone between the substrate and the clade layer and

Table 2. Height and width results obtained for various energy densities.

\begin{tabular}{cccc}
\hline Sample No. & $\begin{array}{c}\text { Clad Width } \\
(\text { micrometer } \mu \mathrm{m})\end{array}$ & $\begin{array}{c}\text { Clad Height } \\
(\text { micrometer } \mu \mathrm{m})\end{array}$ & $\begin{array}{c}\text { Laser energy density } \\
\left(\mathrm{J} / \mathrm{mm}^{3}\right)\end{array}$ \\
\hline A & 9000 & 500 & 30 \\
B & 8000 & 583.3 & 25 \\
C & 7000 & 666.6 & 20 \\
D & 9000 & 333.3 & 31.2 \\
E & 8000 & 333.3 & 26.8 \\
F & 8000 & 666.6 & 23.4 \\
\hline
\end{tabular}

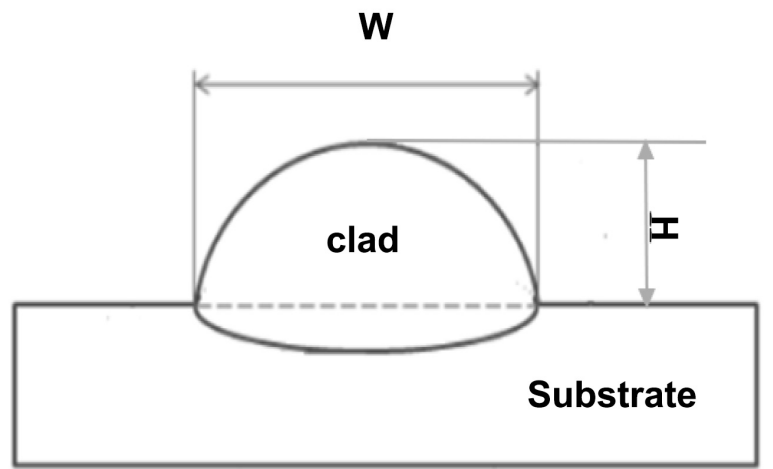

Figure 1. Schematic representation of Height and Width measurement of the clad layer. 


\section{Laser energy denisty Vs Clad Dimensions}

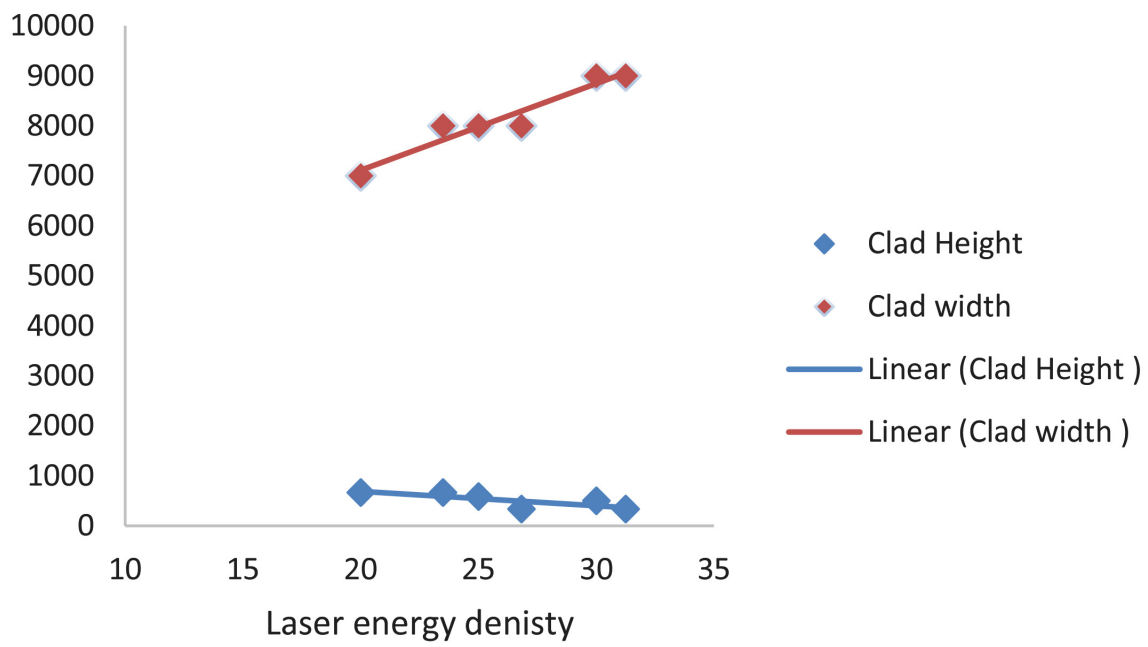

Figure 2. Height and width of the clad vs various Laser energy denisties.
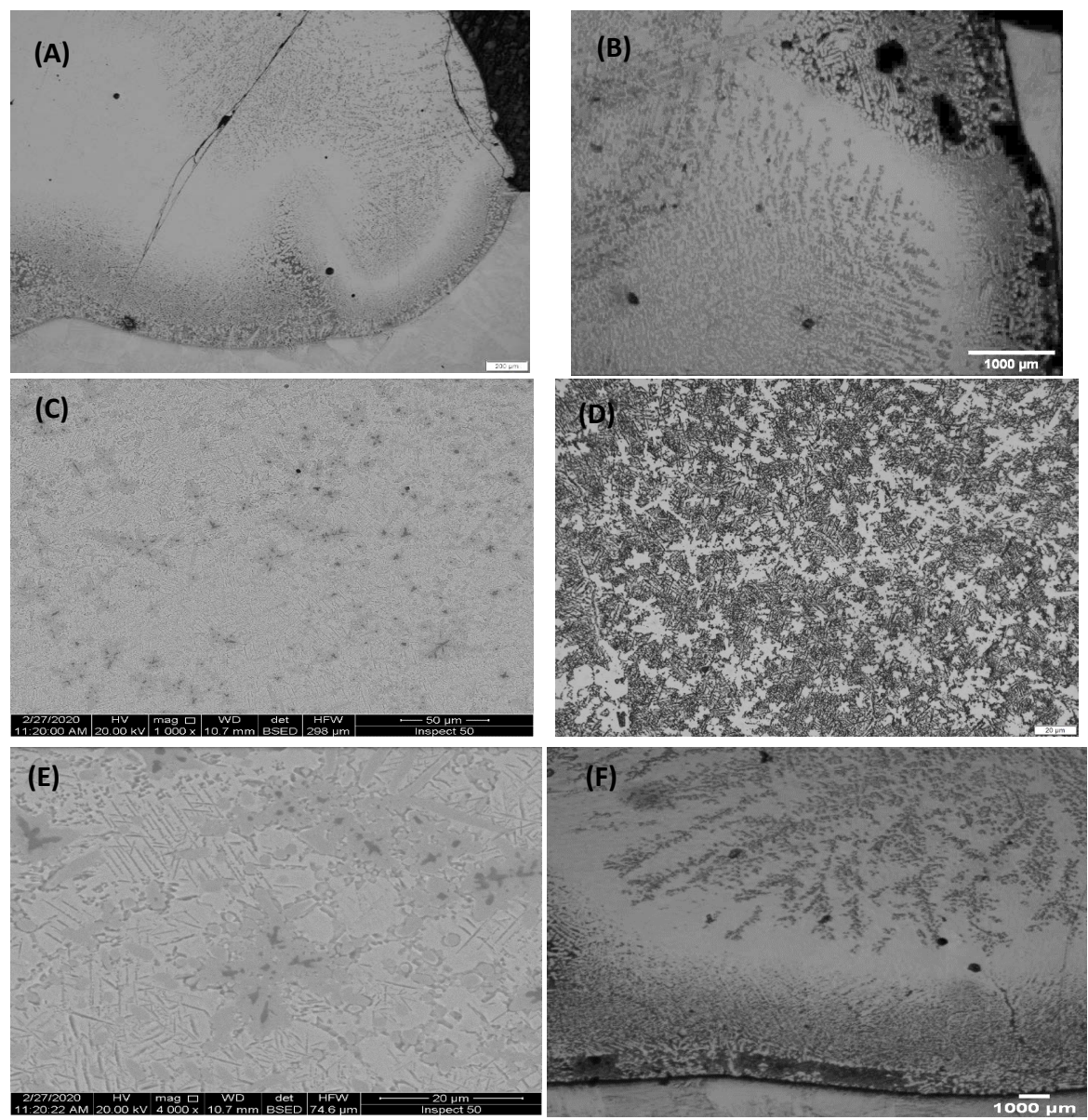

Figure 3. Optical micrographs of the prepared samples. (A) Sample A showing the substrate and diffusion zone and the bottom part of the clad layer; (B) Bottom of Sample E; (C) the middle of Sample H; (D) \& (E) The martensite phase present in Sample H; (F) Micrograph shows the diffusion zone present in all of the samples in addition to the dendrites found. 
along the edges of the clad layer, In addition to the dendrite, there is a crack along the interface between two successive tracks and another one at the right edge of the sample. Furthermore, there are some pores noticed in different areas in the clad layer. Some of the pores found are in a spherical shape, others have irregular shapes and some of them are interconnected. Microstructure of the rest of the samples was investigated, where dendrites arms are present in all of the samples but in different percentages. Sample B and C contained the greatest amount of these dendrites among all of the samples. However, Samples $F$ have finer dendritic structure. Photos of sample B and C show a small percentage of pores present whose shape is spherical. (B) shows the microstructure of Sample $E$ it's clearly observed that it has a great percentage of the dendrite arms in addition to the spherical pores and interconnected ones already found in the sample, furthermore, there is debonding between the substrate and the deposited clad layer. In Sample F it's noticeable that there is a great percentage of the dendrites but a small percentage of pores, there's a debonding between the clad layer and substrate. In micrograph (F) the diffusion zone between the clad layer and the substrate is clear in addition to the dendrites. it was observed after analyzing the microstructure of all of the prepared samples that decreasing the laser power and scan speed leads to the increase of the deposition of second phase precipitates as there is not enough time and heat to melt them while increasing the power and keeping the scan speed constant leads to the decrease of the precipitates. Also decreasing the scan speed while keeping the laser power constant leads to the decrease in the presence of cracks.

Optical micrographs of sample $\mathrm{H}$ show it has small number of pores, however there are some cracks. The area just above the substrate shows that it includes the same dendritic structure which appeared in all the previous samples. The martensite phase is clearly noticed in this sample it is present in almost all the areas above the diffusion zone between the substrate and the clad layer with volume fraction of $40 \%$.

\subsection{Vickers Hardness Test}

Vickers hardness was measured along the length of the clad layer and diffusion zone for each sample as shown in Figure 4 and the average was calculated and listed in Table 3.

Figure 5 and Figure 6 show the relation between Vickers hardness and Laser energy density, laser power and scan speed respectively, it's clear that in samples $\mathrm{A}, \mathrm{B}, \mathrm{C}$ the hardness values increase by decreasing the laser power while keeping the rest of the processing parameters constant, and in Samples D, E, F the hardness values decrease by decreasing the scan speed while keeping the rest of the processing parameters constant. In samples $\mathrm{G}$ and $\mathrm{H}$, the Hardness increased when the rate by which the powder is deposited increased. Also, it's clearly observed that the hardness values increase when the laser energy density increases while keeping the amount of powder deposited constant and this is due to the 


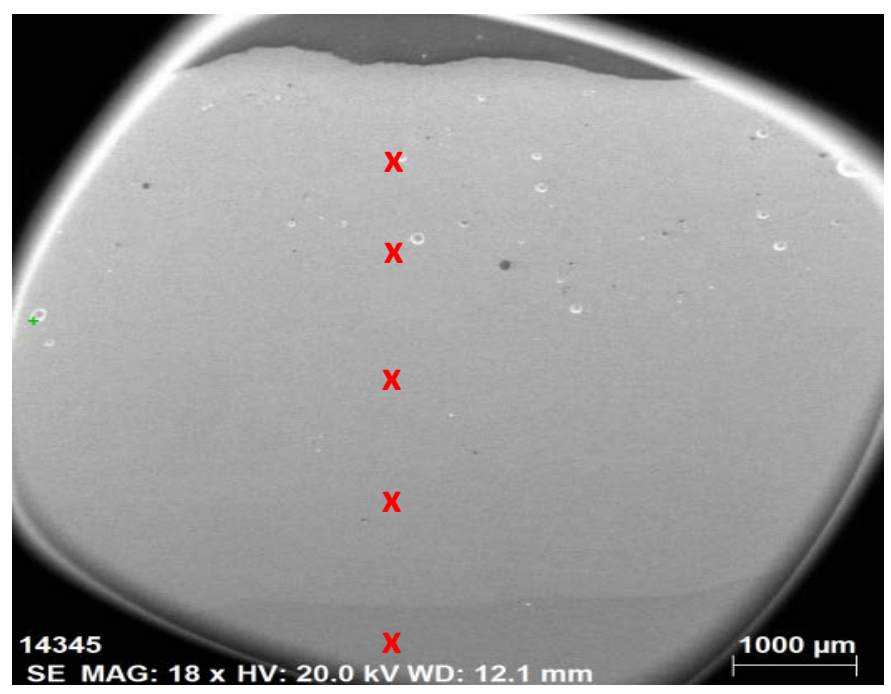

Figure 4. Points at which vickers hardness was measured.

Vickers hardness vs Laser power and Scan speed Laser power Kw

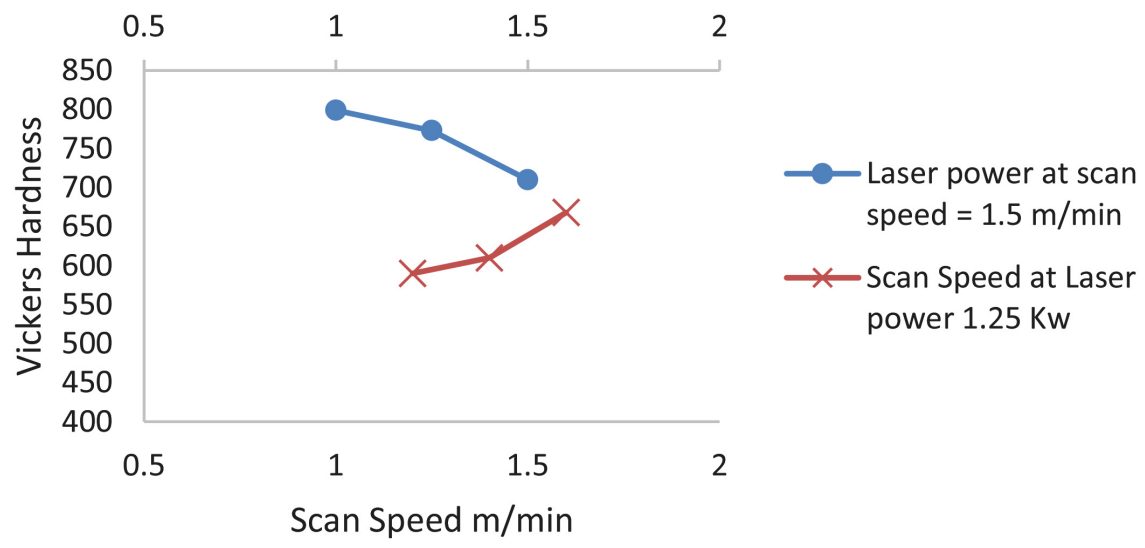

Figure 5. Relation between vickers hardness and scan speed and laser power.

\section{Vickers Hardness Vs Laser energy density}

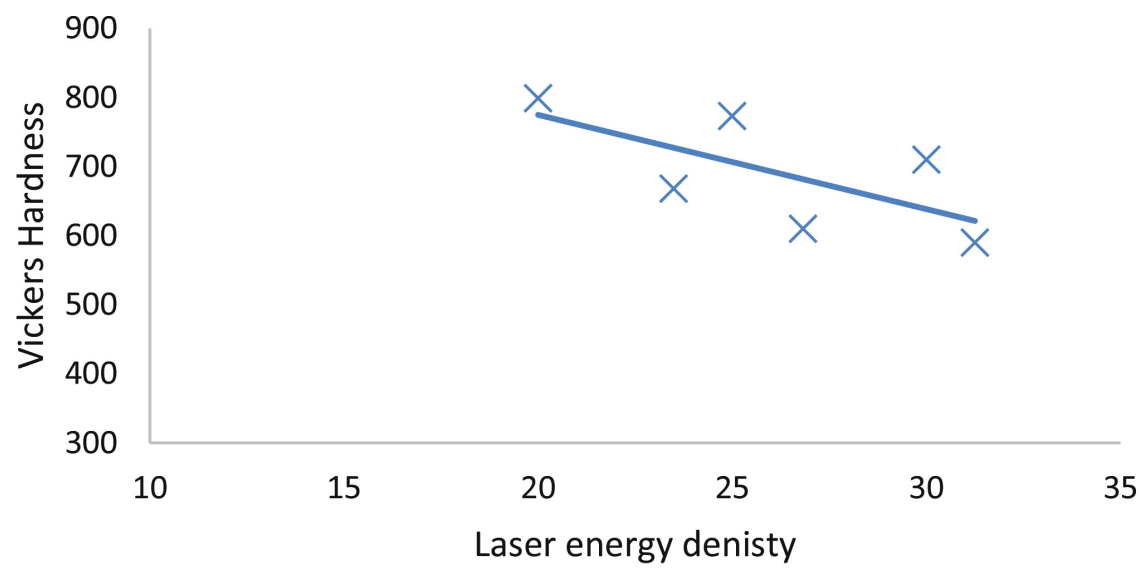

Figure 6. Relation between vickers hardness and laser energy denisty. 
Table 3. Vickers hardness test results.

\begin{tabular}{cc}
\hline Sample No. & Hardness of clad layer $(\mathrm{HV})$ \\
\hline A & 710 \\
B & 773 \\
C & 799 \\
D & 590 \\
E & 610 \\
F & 668 \\
G & 528 \\
H & 598 \\
\hline
\end{tabular}

amount of precipitates found and effect of laser power and scan speed on it. And the rate by which the powder is deposited influences the hardness too, as increasing the amount of the deposited powder of certain elements while keeping the rest of the parameters constant leads to the increase in formation of second phase precipitates which results in the increase in hardness. The hardness value of sample $\mathrm{H}$ which is $598 \mathrm{HV}$ in addition to the presence of martensite phase in its microstructure makes it suitable for the applications that need hard, corrosion resistant and superelastic material such as bearings and gears [18].

\section{Summary and Conclusions}

In this paper, investigation of the effect of the laser cladding processing parameter on microstructure and hardness of nitinol in addition to determining a processing parameter range that shows the best properties in addition to the presence of martensite which is responsible for functional properties like superelasticity and shape memory effect. The following is the summary of the results obtained:

- Clad width of single track is directly proportional to the laser energy density while the clad height of single track is inversely proportional to the laser energy density.

- Decreasing the laser power and scan speed leads to the increase of the deposition of second phase precipitates while increasing the power and keeping the scan speed constant leads to the decrease of the precipitates. Also decreasing the scan speed while keeping the laser power constant leads to a decrease in the presence of cracks.

- It was observed that the martensite phase was present only in the following processing condition, laser power of $1.5 \mathrm{Kw}$, Scan speed of $1.5 \mathrm{~m} / \mathrm{min}$ and rate pf powder deposition of $1.5 / 1.5$, which makes these processing conditions of great interest.

- As for the hardness, it was observed that as the laser energy density increases, hardness increases, however lowering the scan speed led to the decrease in hardness while decreasing the laser power increases the hardness. And the 
rate by which the powder is deposited influences the hardness too, as by increasing the amount of the deposited powder of certain elements while keeping the rest of the parameters constant leads to the increase in hardness.

- For the effect of processing parameters on the clad dimensions, it was concluded that as the energy density increases, the height decreases while keeping the rate of deposited powder constant and the width of the clad layer tends to increase by increasing the laser energy density at a constant powder deposition rate.

- The processing conditions of sample $\mathrm{H}$, which are of laser power of $1.5 \mathrm{Kw}$, the scan speed of $1.5 \mathrm{~m} / \mathrm{min}$ and of laser powder deposition rate of $1.5 / 1.5$, were the most promising ones since it led to a surface with low pores and cracks in addition to the presence of martensite phase which is responsible for the functional properties which make Nitinol a unique alloy in addition to a good hardness value.

\section{Acknowledgements}

This work lies within the frame of project funded by African Laser Centre Research (ALC) Grant-Collaboration Program 2021/2022. Project PI Sisa Pityana, CSIR National Laser Centre, South Africa and Mohamed A. Taha, Faculty of Engineering, Ain Shams University

\section{Conflicts of Interest}

The authors declare no conflicts of interest regarding the publication of this paper.

\section{References}

[1] Elahinia, M. (2015) Shape Memory Alloy Actuators: Design, Fabrication, and Experimental Evaluation. John Wiley and Sons, Hoboken, New Jersey.

https://doi.org/10.1002/9781118426913

[2] Shishkovsky, I., et al. (2008) Porous Biocompatible Implants and Tissue Scaffolds Synthesized by Selective Laser Sintering from Ti and NiTi. Journal of Materials Chemistry, 18, 1309-1317. https://doi.org/10.1039/b715313a

[3] Andani, M.T., et al. (2014) Metals for Bone Implants. Part 1. Powder Metallurgy and Implant Rendering. Acta Biomaterialia, 10, 4058-4070. https://doi.org/10.1016/j.actbio.2014.06.025

[4] Shayesteh Moghaddam, N., et al. (2015) Three Dimensional Printing of Stiffness-Tuned, Nitinol Skeletal Fixation Hardware with an Example of Mandibular Segmental Defect Repair. Procedia CIRP, 49, 45-50. https://doi.org/10.1016/j.procir.2015.07.027

[5] Otsuka, K. and Kakeshita, T. (2002) Science and Technology of Shape-Memory Alloys: New Developments. MRS Bulletin, 27, 91-100. https://doi.org/10.1557/mrs2002.43

[6] Mohd Jani, J., Leary, M., Subic, A. and Gibson, M.A. (2014) A Review of Shape memory Alloy Research, Applications and Opportunities. Materials \& Design, 56, 1078-1113. https://doi.org/10.1016/j.matdes.2013.11.084

[7] Icardi, U. and Ferrero, L. (2009) Preliminary Study of an Adaptive Wing with Shape 
Memory Alloy Torsion Actuators. Materials \& Design, 30, 4200-4210. https://doi.org/10.1016/j.matdes.2009.04.045

[8] Bhardwaj, A., Gupta, A.K., Padisala, S.K. and Poluri, K. (2019) Characterization of Mechanical and Microstructural Properties of Constrained Groove Pressed Nitinol Shape Memory Alloy for Biomedical Applications. Materials Science and Engineering: $C$, 102, 730-742. https://doi.org/10.1016/j.msec.2019.04.070

[9] Chekotu, J.C., Groarke, R., O’Toole, K. and Brabazon, D. (2019) Advances in Selective Laser Melting of Nitinol Shape Memory Alloy Part production. Materials (Basel), 12, Article No. 809. https://doi.org/10.3390/ma12050809

[10] Elahinia, M., et al. (2012) Manufacturing and Processing of NiTi Implants: A Review. Progress in Materials Science, 57, 911-946.

https://doi.org/10.1016/j.pmatsci.2011.11.001

[11] Harun, W.S.W., Kamariah, M.S.I.N., Muhamad, N., Ghani, S.A.C., Ahmad, F. and Mohamed, Z. (2018) A Review of Powder Additive Manufacturing Processes for Metallic Biomaterials. Powder Technology, 327, 128-151.

https://doi.org/10.1016/j.powtec.2017.12.058

[12] Baran, A. and Polanski, M. (2018) Microstructure and Properties of LENS (Laser Engineered Net Shaping) Manufactured Ni-Ti Shape Memory Alloy. Journal of Alloys and Compounds, 750, 863-870. https://doi.org/10.1016/j.jallcom.2018.03.400

[13] Zhang, Y., Wu, L., Guo, X., Kane, S., Deng, Y., Jung, Y.G., Lee, J.H. and Zhang, J. (2018) Additive Manufacturing of Metallic Materials: A Review. Journal of Materials Engineering and Performance, 27, 1-13. https://doi.org/10.1007/s11665-017-2747-y

[14] Yusuf, S.M. and Gao, N. (2017) Influence of Energy Density on Metallurgy and Properties in Metal Additive Manufacturing. Materials Science and Technology, 33, 1269-1289. https://doi.org/10.1080/02670836.2017.1289444

[15] de Oliveira, U., Ocelík, V. and De Hosson, J.T.M. (2005) Analysis of Coaxial Laser Cladding Processing Conditions. Surface and Coatings Technology, 197, 127-136. https://doi.org/10.1016/j.surfcoat.2004.06.029

[16] Ya, W., Pathiraj, B. and Liu, S. (2016) 2D Modelling of Clad Geometry and Resulting Thermal Cycles during Laser Cladding. Journal of Materials Processing Technology, 230, 217-232. https://doi.org/10.1016/j.jmatprotec.2015.11.012

[17] Noskov, A.I., Gilmutdinov, A.K. and Yanbaev, R.M. (2017) Effect of Coaxial Laser Cladding Parameters on Bead Formation. International Journal of Minerals, Metallurgy, and Materials, 24, 550-556. https://doi.org/10.1007/s12613-017-1436-Z

[18] Stanford, M.K. (2016) Hardness and Microstructure of Binary and Ternary Nitinol Compounds. National Aeronautics and Space Administration, Cleveland, Ohio, $46 \mathrm{p}$. http://www.sti.nasa.gov 